\title{
Modeling of Yield Losses Caused by Potato Late Blight on Eight Cultivars with Different Levels of Resistance to Phytophthora infestans
}

Toky Rakotonindraina, INRA, UMR 1248 AGIR, 31326 Castanet Tolosan Cedex, France; Jean-Éric Chauvin and Roland Pellé, INRA, UMR APBV, Domaine de Kéraïber, 29260 Ploudaniel, France; Robert Faivre, INRA, UMR BIA, 31326 Castanet Tolosan Cedex, France; Catherine Chatot, Germicopa R\&D, Kerguivarch, 29520 Châteauneuf du Faou, France; and Serge Savary and JeanNoël Aubertot, INRA, UMR 1248 AGIR, 31326 Castanet Tolosan Cedex, France

\begin{abstract}
Rakotonindraina, T., Chauvin, J.-E., Pellé, R., Faivre, R., Chatot, C., Savary, S., and Aubertot, J.-N. 2012. Modeling of yield losses caused by potato late blight on eight cultivars with different levels of resistance to Phytophthora infestans. Plant Dis. 96:935-942.

The Shtienberg model for predicting yield loss caused by Phytophthora infestans in potato was developed and parameterized in the 1990 s in North America. The predictive quality of this model was evaluated in France for a wide range of epidemics under different soil and weather conditions and on cultivars different than those used to estimate its parameters. A field experiment was carried out in 2006, 2007, 2008, and 2009 in Brittany, western France to assess late blight severity and yield losses. The dynamics of late blight were monitored on eight cultivars with varying types and levels of resistance. The

mean square error of prediction $=13.25 \%$, and bias $=-0.36 \%$ ) as a function of weather and the observed disease dynamics for a wide range of late blight epidemics. In addition to the evaluation of the predictive quality of the model, this article provides a dataset that describes the development of various late blight epidemics on potato as a function of weather conditions, fungicide regimes, and cultivar susceptibility. Following this evaluation, the Shtienberg model can be used with confidence in research and development programs to better manage potato late blight in France.
\end{abstract} model correctly predicted relative yield losses (efficiency $=0.80$, root
Potato (Solanum tuberosum) is a major food crop grown in most countries of the world. It is the third crop in order of importance consumed by humans, behind wheat and rice (13). Late blight, caused by the oomycete Phytophthora infestans (Mont.) de Bary, is the most limiting production factor for potato (6). This disease may cause severe yield losses, especially under favorable conditions for $P$. infestans, if left uncontrolled (11). Therefore, it is necessary to analyze crop losses, especially yield losses, in order to develop efficient control strategies.

Several yield-loss-assessment models in potato have been developed for late blight. However, the modeling approaches that have been used thus far mostly rely on statistical relationships between a variable describing the severity of the disease and yield loss, as exemplified by the pioneering work by Large (20) in England. This critical-stage method showed that yield loss could be predicted as a function of the date at which $75 \%$ of the crop green area foliage had been injured by the disease. Other statistical models have been used to determine critical thresholds for potato late blight. For instance, in the critical-injury-threshold model developed by Olofsson (28) in Sweden, yield loss was inversely proportional to the period during which the culture was disease free. The "multiple-point methods" derived from multiple regression analyses, developed by James et al. (14) in Canada, determined the potato yield loss as the sum over time of disease increments, weighted by the weekly progress of the epidemic (21). Many of these models have shown limitations when used under conditions that differ from those where their parameters were estimated. For instance, the critical-injury-threshold method developed by Olofsson (28) in Sweden was inappropriate for Canadian conditions (14)

Corresponding author: J. N. Aubertot,

E-mail: Jean-Noel.Aubertot@toulouse.inra.fr

Accepted for publication 1 December 2011.

http://dx.doi.org/10.1094/PDIS-09-11-0752

() 2012 The American Phytopathological Society
In complement to statistical approaches, mechanistic representations of processes can be developed to create models less dependent on the dataset used to estimate their parameters. The mechanistic model developed by Shtienberg et al. (35) in New York in the United States predicts yield losses as a function of the dynamics of foliar injuries caused by $P$. infestans, cultivar characteristics, and weather conditions. Yield accumulation is a function of the crop's physiological age and the maximum bulking rate. The model estimates yield losses based on the reduction of tuberization due to epidemics, while taking into account the type and level of resistance of the considered cultivar as well as interactions with environmental conditions. This model presents several advantages: (i) its mechanistic structure could ensure some robustness with regard to the considered production situation, (ii) it has few parameters, and (iii) its input variables are easy to characterize and measure.

In this article, we evaluated the Shtienberg model on different cultivars and under soil and weather conditions other than where it had been initially parameterized. The hypothesis tested in this study was that the model accurately predicts potato yield losses for various French potato cultivars under soil and weather conditions of Brittany, France. This article presents the results obtained in a 4year experiment in terms of foliar injury due to potato late blight and the associated yield loss, along with an assessment of the predictive quality of the Shtienberg model (35). The results are discussed with regard to their contribution to the control of potato late blight and their implication for the design of integrated pest management (IPM) or integrated crop management strategies $(4,8,9)$ against potato late blight.

\section{Materials and Methods}

Experiment details. An experiment was carried out over four consecutive years in 2006, 2007, 2008, and 2009 at the INRA experimental station of Ploudaniel $\left(48^{\circ} 32^{\prime} 13^{\prime \prime} \mathrm{N}, 04^{\circ} 18^{\prime} 47^{\prime \prime} \mathrm{W}\right.$, Brittany, France) to analyze yield losses caused by $P$. infestans on eight potato cultivars ('Arka', 'Bintje', 'Désirée', 'Eden', 'INRA 92T 114 76', 'INRA 92T 120 16,' 'Naturella', and 'Robijn') with different types and levels of genetic resistance to late blight. Bintje and Désirée are susceptible cultivars. INRA 92T 12016 carries an effective resistance $(R)$ gene which has not yet been overcome by 
the $P$. infestans strains present in France. This resistance source comes from the CIP A population (19), which was introduced into France in 1982. Naturella carries the $S$. demissum $R 2$ gene which is overcome by many $P$. infestans strains (30). Arka possesses at least $1 R$ gene, from the wild species $S$. demissum (17), which is overcome by P. infestans. Robijn and INRA 92 T 11476 present a moderate level of partial resistance. However, no genetic study has been made on these genotypes to determine the origin of these resistances (i.e. the number, size, and locations of the quantitative trait loci involved).

In order to assess yield losses, yields were measured on nontreated and treated plots with preventive fungicides against late blight. Treatments consisted of applying alternating contact and systemic fungicides (e.g., Milcozebe with the contact activity of mancozeb; or Tattoo $\mathrm{C}$, which combines the systemic action of propamocarb hydrochloride with the contact activity of chlorothalonil) every 7 to 10 days, depending on the intensity of epidemics. The number of treatments met the recommendations for use of licensed products to avoid selection of pathogen strains resistant to the active compounds. The potato crops were naturally infected by local strains of $P$. infestans.

The experimental design was an $\alpha$-lattice design with 48 plots (eight cultivars $\times$ two fungicide regimes $\times$ three replicates). Each experimental unit consisted of 20 plants, planted at a spacing of $0.32 \mathrm{~m}$ between plants and $0.70 \mathrm{~m}$ between rows. The size of each plot was $4.48 \mathrm{~m}^{2}$. These plots were arranged in rows and columns to control field heterogeneity. Each plot was delimited by a row of Bintje (a susceptible cultivar) used as an inoculum spreader.

Four types of measurements were made. An automatic weather station monitored relative humidity, rainfall, global radiation, and daily minimum, maximum, and mean temperatures. The model requires the minimum and the maximum daily temperatures as input variables to calculate physiological ages (detailed in equation 4.) In this study, disease epidemics were visually assessed from emergence until the end of the vegetative period. Disease severities were monitored weekly by estimating the proportion of diseased leaf area $(1,23)$ using a scoring method adapted from the National Agricultural Advisory Service visual assessment key, promoted by the Disease Measurement Committee of the British Mycological Society (20). The severity scale of this visual assessment key is detailed in Table 1. Various raters quantified the severity of the disease. In order to prevent any bias due to different appreciations of raters, each block was assessed by the same rater for each year of the experiment. This minimized any potential rater effect with the block effect, as recommended by Aubertot et al. (3).

At the end of the season, yield (i.e., the mass of tubers per cultivated area unit) was measured for each plot. Relative yield loss was calculated for each cultivar and each replicate using the actual yield $\left(Y_{\text {act }} ; 27,29,32-34\right)$ measured on diseased plants (untreated plot) and the attainable yield $\left(Y_{\text {att }} ; 27,29,32-34\right)$ measured on healthy plants (treated plot) using the following equation:

$R Y L_{i j}=100 \times\left(\frac{Y_{a t t}^{i j}-Y_{a c t}^{i j}}{Y_{a t t}^{i j}}\right)$ where $R Y L_{i j}$ is the relative yield loss for cultivar $i$, replicate $j ; Y_{a t t}^{i j}$ is the attainable yield for cultivar $i$, replicate $j$; and $Y_{a c t}^{i j}$ is the actual yield for cultivar $i$, replicate $j$.

Yield loss modeling. The basic principle of the model developed by Shtienberg et al. (35) is to represent yield reduction due to foliar injury caused by $P$. infestans. Foliar injury is described by an area under the disease progress curve (AUDPC; 5,15). This model does not take into account losses caused by direct infection of tubers.

The level of cultivar resistance is not taken into account by the model, because it is already embedded with the input variable that describes the disease epidemics. However, the three input variables associated with the "cultivar maturity class" (B, bulking rate for the disease free crop; $P_{\mathrm{tg}}$, physiological age at the bulking initiation for a healthy crop; and $P_{\mathrm{cg}}$, physiological age at the end of bulking for a healthy crop) can be seen as criteria which also express some level of tolerance because they directly modify the injury-damage relationship $(32,41)$.

The variables and parameters of this model are listed in Table 2 and parameter values are given in Table 3 . In this model, the relative yield loss was calculated as follows:

$$
R Y L=100\left\{1-\left[1-\frac{\alpha\left(R A U D P C_{\mathrm{inf}}-R A U D P C_{r e f}\right)}{B}\right]\left(\frac{P_{c b}^{\prime}-P_{t g}^{\prime}}{P_{c b}-P_{t g}}\right)\right\}
$$

The symbols used in equation 2 are explained in Table 2. The terms $\left(P_{c b}^{\prime}-P_{c g}^{\prime}\right)$ and $\left(P_{c b}-P_{t g}\right)$ represent the thermal time needed for tuberization for a healthy and an infected crop respectively and $R A U D P C$ is the relative AUDPC. The difference between the $R A U D P C$ of an infected crop and a reference crop is used to predict yield loss due to potato late blight (16). It is calculated as follows:

$$
R A U D P C=\frac{1}{P_{\max }-P_{1}} \sum_{i=1}^{i=n}\left(\frac{X_{i+1}+X_{i}}{2}\right)\left(P_{i+1}-P_{i}\right)
$$

where $i$ refers to the rank of observations ranging from 1 to $n, n$ is the total number of observations, $X$ is the proportion of defoliation (or proportion of diseased foliage), $P_{\max }$ is the maximum physiological age, and $P_{1}$ is the physiological age for the first observation. In this study, the severity of the disease on the reference crop was always taken as zero (the severity was insignificant) because almost no disease was observed in the treated plots of the experiment. The physiological ages used in equation 2 are calculated as presented in equation $4(10,24,31,39)$.

$$
\begin{aligned}
& \text { Pday }=\frac{1}{\Delta t_{1}}\left[\begin{array}{l}
\Delta t_{2} P\left(\theta_{\text {min }}\right)+\Delta t_{3} P\left(\mathrm{a} \theta_{\text {min }}+b \theta_{\text {max }}\right)+ \\
\Delta t_{3} P\left(\mathrm{a} \theta_{\text {max }}+b \theta_{\text {min }}\right)+\Delta t_{4} P\left(\theta_{\text {max }}\right)
\end{array}\right] \\
& \text { with } \Delta t_{1}=24 \mathrm{~h}, \Delta t_{2}=5 \mathrm{~h}, \Delta t_{3}=8 \mathrm{~h}, \Delta t_{4}=3 \mathrm{~h}, a=2 / 3, b=1 / 3 . \\
& P_{x}=\sum_{i=1}^{i=x} P d a y
\end{aligned}
$$

$P(\theta)$ is the rate of development, expressed in p-days/day, whose value depends on the temperature $\theta(31)$. This function is defined as follows:

Table 1. Visual assessment key used to estimate disease severity in observed data (20)

\begin{tabular}{ll}
\hline Blight (\%) & \multicolumn{1}{c}{ Description of visual assessment } \\
\hline 0.0 & No symptom in the plot \\
0.1 & Only a few plants affected here and there, up to 4 spots per plot \\
1.0 & Up to 10 spots per plot \\
5.0 & About 50 spots per plot or general light spotting \\
10.0 & Up to 10\% of leaves per plot destroyed, the plot looks green \\
25.0 & Up to 25\% of leaves per plot destroyed, nearly every leaflet with lesions, the plot looks green flecked with brown \\
50.0 & Up to 50\% of leaves per plot destroyed, the plot looks neither predominantly brown nor green \\
75.0 & Up to 75\% of leaves per plot destroyed, the plot looks predominantly brown \\
90.0 & Up to 90\% of leaves per plot destroyed \\
95.0 & Up to 95\% of leaves per plot destroyed, only a few leaves left green, part of the stems are still green \\
100 & No more green part in the plot, all part of plants are brown \\
\hline
\end{tabular}


If $\theta<\theta_{\text {inf }}$ or $\theta>\theta_{\text {sup }}$, then $P(\theta)=0$ p-days

If $\theta_{i n f} \leq \theta<\theta_{o p t}$, then $P(\theta)=k\left[1-\frac{\left(\theta-\theta_{\text {opt }}\right)^{2}}{\left(\theta_{\text {opt }}-\theta_{\text {inf }}\right)^{2}}\right]$

If $\theta_{\text {opt }} \leq \theta \leq \theta_{\text {sup }}$, then $P(\theta)=k\left[1-\frac{\left(\theta-\theta_{\text {opt }}\right)^{2}}{\left(\theta_{\text {sup }}-\theta_{\text {opt }}\right)^{2}}\right]$

with $\theta_{\text {inf }}=7^{\circ} \mathrm{C}, \theta_{\text {opt }}=21^{\circ} \mathrm{C}, \theta_{\text {sup }}=30^{\circ} \mathrm{C}, k=10$ p-days, and $\theta_{\text {min }}$ and $\theta_{\max }$ referring to the minimum and maximum daily temperature, respectively.

The daily temperature changes over time were described using a sine function (40). The integration of these changes occurring during 1 day in the modeling of physiological age can be achieved using equation 4. Alternatively, these daily changes could also be represented more simply by considering the mean value of the effective vegetative development temperature of potato on a given day (equation 7). This second method was also used to calculate the physiological day in order to test its predictive quality.

$P$ day $=\frac{1}{2}\left[P\left(\theta_{\min }\right)+P\left(\theta_{\max }\right)\right]$

Statistical analysis. Shapiro tests showed that some of the observed data were not normally distributed. Therefore, the nonparametric tests of Mann-Whitney and Kruskal-Wallis were used for the comparison of relative yield losses among cultivars using the $\mathrm{R}$ software (12), version 2.10.0. The predictive quality of the model of Shtienberg (35) was characterized using three statistical criteria: bias, root mean square error of prediction (RMSEP), and efficiency $(18,25,26,36,38)$ :
Bias $=\frac{1}{N} \sum_{i=1}^{i=N}\left(Y_{i}^{o b s}-Y_{i}^{s i m}\right)$

where $N$ is the total number of situations, $Y_{i}^{\text {obs }}$ is the observed value for situation $i$, and $Y_{i}^{\operatorname{sim}}$ is the corresponding value simulated by the model. The bias measures the average difference between observed and simulated values. If the model underestimates the considered variable, the bias is positive. Conversely, if the model overestimates the variable, the bias is negative.

$$
R M S E P=\sqrt{\frac{1}{N} \sum_{i=1}^{i=N}\left(Y_{i}^{s i m}-Y_{i}^{\text {obs }}\right)^{2}}
$$

RMSEP quantifies the prediction error when the model parameters have not been estimated using the observations $Y_{i}^{\text {obs }}$ used in the calculation of this criterion.

$$
\text { Efficiency }=1-\frac{\sum_{i=1}^{i=N}\left(Y_{i}^{s i m}-Y_{i}^{o b s}\right)^{2}}{\sum_{i=1}^{i=N}\left(Y_{i}^{o b s}-\bar{Y}^{o b s}\right)^{2}}
$$

where $\bar{Y}^{\text {obs }}$ is the mean of observed data. Nash and Sutcliffe (26) defined "efficiency" as a normalized statistic that determines the relative magnitude of the residual variance ("noise") compared with the measured data variance ("information"). The efficiency defines the ability of a model to predict the value of a variable. The efficiency can range from $-\infty$ to $1(18,25,26,36,38)$. If the model perfectly predicts the observations, the efficiency is maximum and is equal to 1 . Efficiency values lower than 0 indicate that the mean observed values is a better predictor than the simulated values, which indicate a poor predictive quality of the model $(18,25,26,36,38)$. Values between 0 and 1 are generally viewed as acceptable levels of performance $(18,25,26,36,38)$. The closer the

Table 2. Input variables, state variables, and output variable of the model developed by Shtienberg et al. (35) to represent yield loss as a function of potato

\begin{tabular}{|c|c|c|}
\hline Variables & Symbol & Unit \\
\hline \multicolumn{3}{|l|}{ Input variables } \\
\hline Bulking rate for the disease free crop, cultivar dependent & B & t/hap-days \\
\hline Minimum daily temperature & $\theta_{\min }$ & ${ }^{\circ} \mathrm{C}$ \\
\hline Maximum daily temperature & $\theta_{\max }$ & ${ }^{\circ} \mathrm{C}$ \\
\hline Physiological age at the bulking initiation for a healthy crop, cultivar dependent & $P_{\mathrm{tg}}$ & p-days \\
\hline Physiological age at the end of bulking for a healthy crop, cultivar dependent & $\mathrm{P}_{\mathrm{cb}}$ & p-days \\
\hline \multicolumn{3}{|l|}{ State variables } \\
\hline Physiological age (10) & $\mathrm{P}$ & p-days \\
\hline Physiological age at the first observation & $\mathrm{P}_{1}$ & p-days \\
\hline Physiological age at the $i$ th observation & $\mathrm{P}_{\mathrm{i}}$ & p-days \\
\hline Physiological age at the bulking initiation for an infected crop, cultivar dependent & $\mathrm{P}_{\mathrm{tg}}^{\prime}$ & p-days \\
\hline Physiological age at the end of bulking for an infected culture, cultivar dependent & $\mathrm{P}_{\mathrm{cb}}^{\prime \prime}$ & p-days \\
\hline Maximum physiological age & $\mathrm{P}_{\max }$ & p-days \\
\hline Relative area under the disease progress curve for the reference crop & RAUDPC $_{\text {ref }}$ & $\ldots$ \\
\hline Relative area under the disease progress curve for the infected crop, cultivar dependent & RAUDPC $_{\text {inf }}$ & $\ldots$ \\
\hline Proportion of diseased foliar area for the $i$ th observation & $\mathrm{X}_{\mathrm{i}}$ & $\ldots$ \\
\hline \multicolumn{3}{|l|}{ Output variable } \\
\hline Relative yield loss & RYL & $\%$ \\
\hline
\end{tabular}
late blight dynamic

\begin{tabular}{|c|c|c|c|}
\hline Parameter & Symbol & Value & Unit \\
\hline Coefficient of maximum bulking rate reduction (35) & $\alpha$ & 0.252 & t/ha p-days \\
\hline Length of a day (31) & $\Delta t_{1}$ & 24 & $\mathrm{H}$ \\
\hline Duration of the effective vegetative development at $\theta_{\min }(31)$ & $\Delta t_{2}$ & 5 & $\mathrm{H}$ \\
\hline Duration of the effective vegetative development between $\theta_{\min }$ and $\theta_{\max }(31)$ & $\Delta t_{3}$ & 8 & $\mathrm{H}$ \\
\hline Duration of the effective vegetative development at $\theta_{\max }(31)$ & $\Delta t_{4}$ & 3 & $\mathrm{H}$ \\
\hline Minimum temperature for plant growth (31) & $\theta_{i n f}$ & 7 & ${ }^{\circ} \mathrm{C}$ \\
\hline Optimum temperature for plant growth (31) & $\theta_{o p t}$ & 21 & ${ }^{\circ} \mathrm{C}$ \\
\hline Maximum temperature for plant growth (31) & $\theta_{\text {sup }}$ & 30 & ${ }^{\circ} \mathrm{C}$ \\
\hline Proportion of plant growth dependence on $\Delta t_{3}(31)$ & $a$ & $2 / 3$ & $\ldots$ \\
\hline Proportion of plant growth dependence on $\Delta t_{3}(31)$ & $b$ & $1 / 3$ & $\ldots$ \\
\hline Scale factor (31) & $k$ & 10 & p-days \\
\hline
\end{tabular}

Table 3. Parameter values used in the Shtienberg yield loss model 
model efficiency to 1 , the better is the fit between observed and simulated data $(18,25,26,36,38)$. The distribution of model residuals (observed relative yield losses minus predicted relative yield losses) was analyzed.

\section{Results}

Temporal dynamics of potato late blight. Disease dynamics depended strongly on weather conditions (Fig. 1). The year 2006 was an unfavorable for potato late blight, and the epidemic was delayed. By contrast, the 2007 epidemic was very severe. The epidemic onset was early and rapidly caused severe injury. The early onset of the disease completely destroyed the culture. This prevented the formation of a tuber or reduced the tuberization if it had already started. Yield accumulation was interrupted and yield
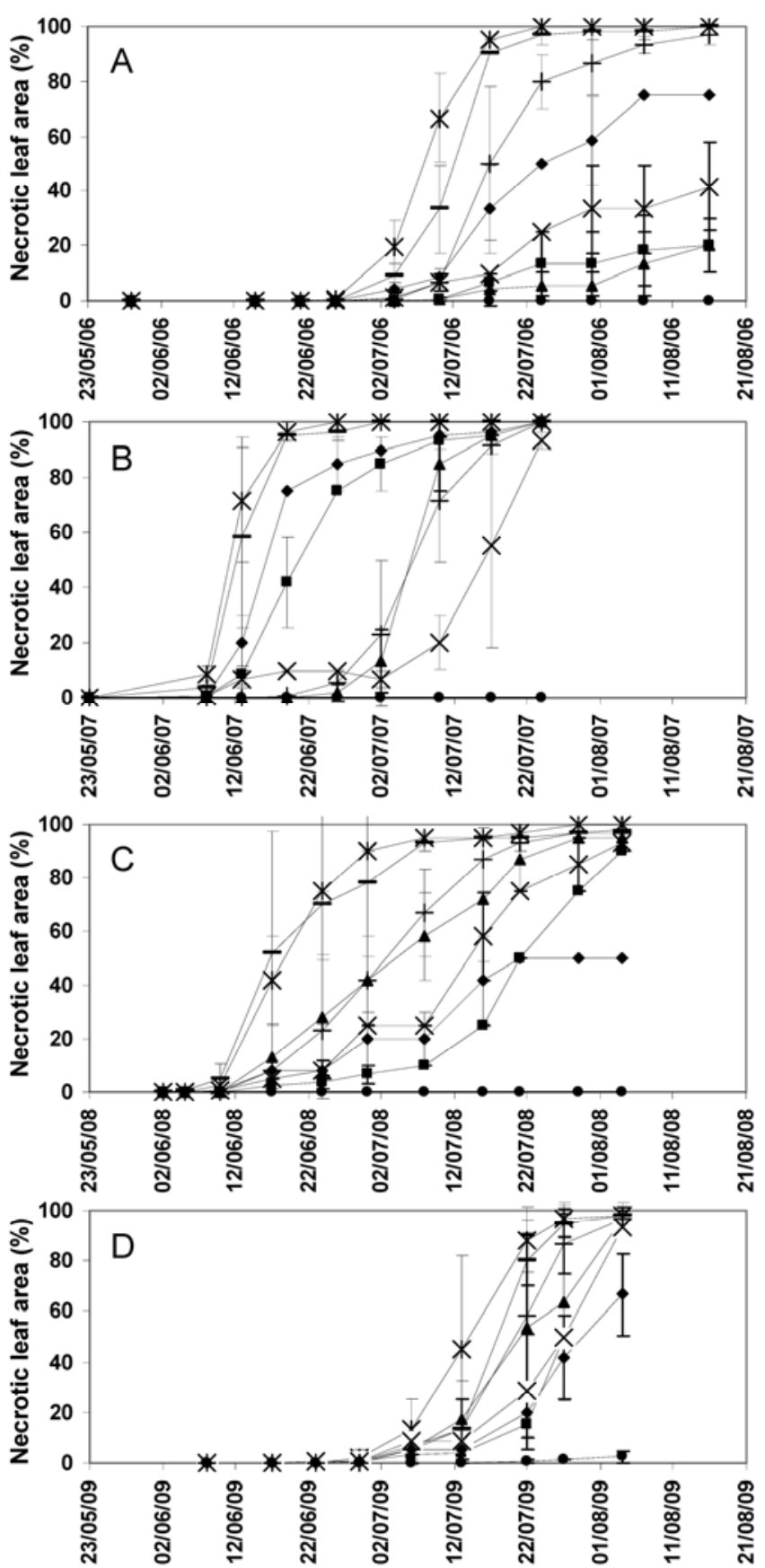

Fig. 1. Percentage of leaf area injured by potato late blight for eight cultivars in a 4year experiment conducted at the INRA Ploudaniel station (Brittany, France). Disease dynamics in A, 2006; B, 2007; C, 2008; and D, 2009. Each symbol represents a cultivar: - Arka; *, Bintje; -, Désirée; $\mathbf{\Lambda}$, Eden; x, INRA 92T 114 76; •, INRA 92T 120 $16 ;+$, Naturella; $\downarrow$, Robijn. Error bars represent the $95 \%$ confidence intervals. losses were high. The year 2008 was similar to 2007 but with a weaker epidemic and lower yield losses. In 2009, the disease was severe but its establishment was late in the season. Weather conditions (temperature and humidity) were favorable to the development of late blight in 2007 and 2008 compared with 2006 and 2009. The timing of epidemic onset, which is also weather dependent, influenced yield losses, too.

Epidemics also depended very much on cultivars (Fig. 1). INRA 92T 12016 differed significantly from other cultivars because it showed no injury except at the end of 2009 (Fig. 1).

Bulking duration. The bulking duration is defined as the difference in physiological age (expressed in p-days) from tuber initiation to the end of tuberization. Bulking duration depends on the cultivar maturity class. In our experiment, it varied from 350 (Bintje) to 480 (Robijn) p-days for disease-free cultivars (Fig. 2, hatched white bars). These values were used as references for estimating relative yield losses using equation 2. Bulking durations declined with the severity of the late blight epidemics (Fig. 2). The average was 418 p-days for the eight disease-free cultivars, and fell to 333, 109, 130, and 212 p-days in 2006, 2007, 2008, and 2009 respectively. Bulking durations in 2007 were the shortest because the epidemic was the strongest that year. They were longest in 2006 and intermediate in 2008 and 2009. These results are consistent with the observed disease dynamics (Fig. 1).

Relative yield losses. Yield losses depended strongly on the cultivars (Fig. 3, p $=4.0 \times 10^{-5}$, Kruskall-Wallis test), not only because epidemics depended on cultivar susceptibility (Table 4) but also because the damage function of potato late blight is cultivar dependent. INRA 92T 12016 differed from other cultivars because it was the only cultivar without any loss until 2008, and a slight relative yield loss (5\%) in 2009 (Fig. 3). The Mann-Whitney test classified the observed relative yield losses into three groups. The first group was composed only of INRA 92T 120 16, the only cultivar without any significant loss. Another group consisted of cultivars with severe relative yield losses (Bintje and Désirée). Finally, the remaining cultivars (Eden, INRA 92T 114 76, Robijn, Naturella, and Arka) can be considered as an intermediate group and were statistically different from the first two groups.

Relative yield losses also differed from one year to another ( $\mathrm{p}=$ $3.9 \times 10^{-9}$, Kruskal-Wallis test). For instance, yield losses for the susceptible Bintje did not exceed $62 \%$ in 2006, whereas they were more than $93 \%$ in 2007 and 2008 before declining to 54\% in 2009. Generally, relative yield losses were significantly higher in 2007 and 2008 than in 2006 and 2009 ( $\mathrm{p}=7.0 \times 10^{-11}$, Mann-Whitney test). These results are consistent with the observed disease dynamics (Fig. 1).

In addition, interactions between cultivar and year were observed. For instance, 2008 was, in general, favorable to late blight and caused significant losses for most cultivars. However, Arka was unusually slightly susceptible to the disease in that year and experienced lower losses than other cultivars. Arka was also slightly affected by the disease in 2006 (with $25 \%$ relative yield loss) but became as susceptible as Bintje in 2007 (96\% relative yield loss). Naturella was more sensitive to the disease than Arka in 2006 (with $47 \%$ relative yield loss) and was less susceptible than Arka in 2007 (with 66\% relative yield loss).

Evaluation of the predictive quality of the Shtienberg model. The overall predictive quality of the model was good (Fig. 4). The model's predictive quality was also good because the efficiency value was high (i.e., close to 1). The RMSEP was quite low $(13.25 \%)$, although the model slightly overestimated relative yield losses (bias $=-0.36 \%$ ). The residuals were quite evenly distributed over a wide range of yield losses (from 5 to 100\%). Importantly, the model was successful in representing the year-to-year variability as well as the intercultivar variability of potato late blight epidemics. Residuals were randomly distributed around zero, indicating that the predictions of the model were independent of the observed yield losses (Fig. 5).

The calculation of physiological age just using the mean effective vegetative development between the minimum and maximum 
daily temperature slightly improved the efficiency of the model (0.81) and slightly decreased the RMSEP (12.89\%). However, the overall bias of the model was increased $(-5.60 \%)$ when physiological ages were calculated using this simpler method.

\section{Discussion}

This study provides experimental data about the effects of various levels of cultivar resistance on leaf disease caused by $P$. infestans and the associated damage for a wide range of late blight epidemics in France. In order to characterize disease, the studied variable was the relative yield loss in order to compare cultivars with different potential yields. However, if the cultivars are to be assessed with regard to their production performance, it is the actual yield that should be considered. In this experiment, attainable yields ranged from 24 to $94 \mathrm{t} / \mathrm{ha}$ in $2006,0.3$ to $64 \mathrm{t} / \mathrm{ha}$ in 2007,2 to $85 \mathrm{t} / \mathrm{ha}$ in 2008 , and 26 to $83 \mathrm{t} / \mathrm{ha}$ in 2009 . The ranking of the eight studied cultivars according to their susceptibility is in agreement with the available knowledge on the late blight genetic resis-

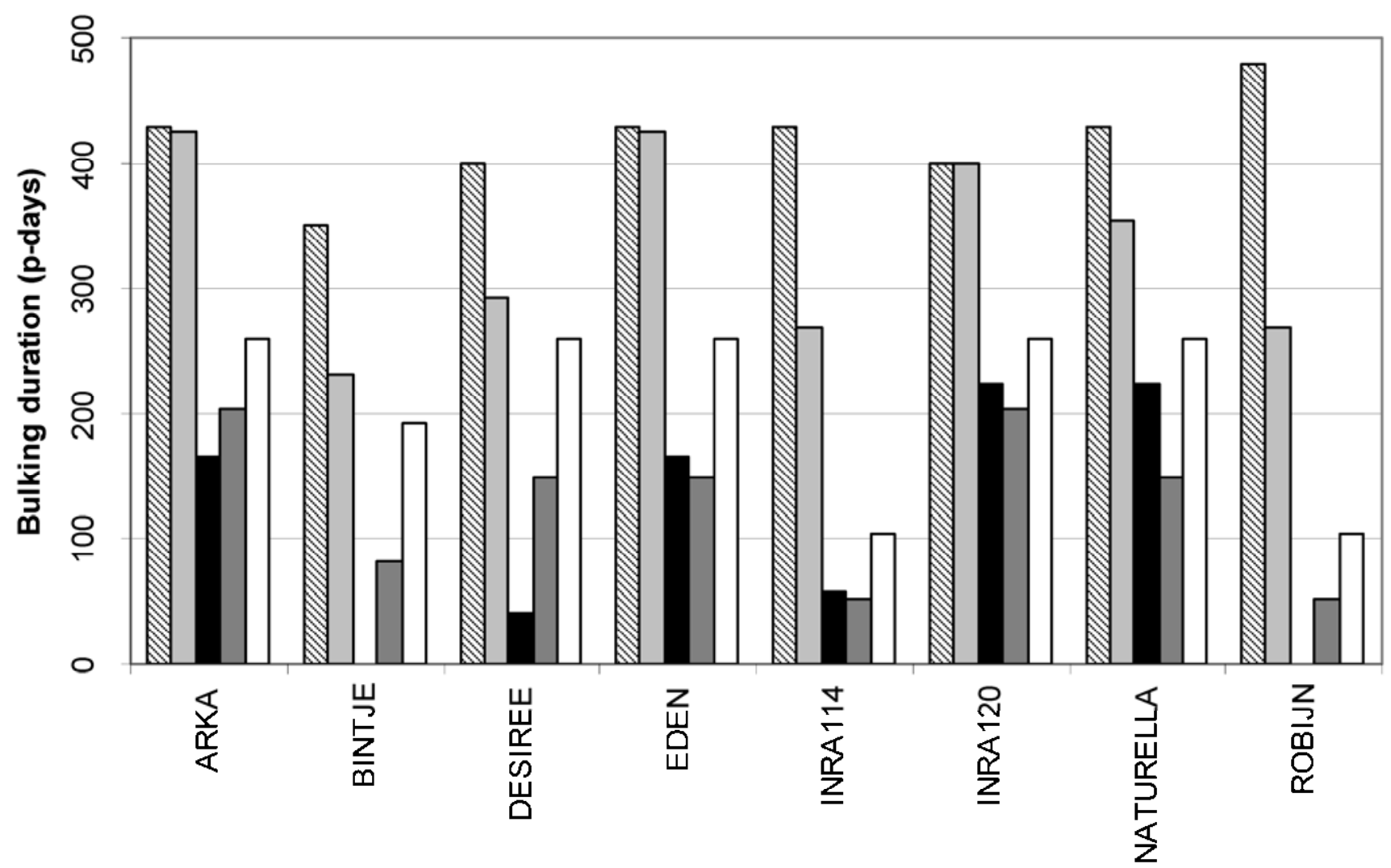

Fig. 2. Bulking duration for eight cultivars in the 4year experiment conducted at the INRA Ploudaniel station (Brittany, France). The bar color represents the year of observation: light gray (2006), black (2007), dark gray (2008), and white (2009). Hatched bars represent bulking duration for healthy cultivars.

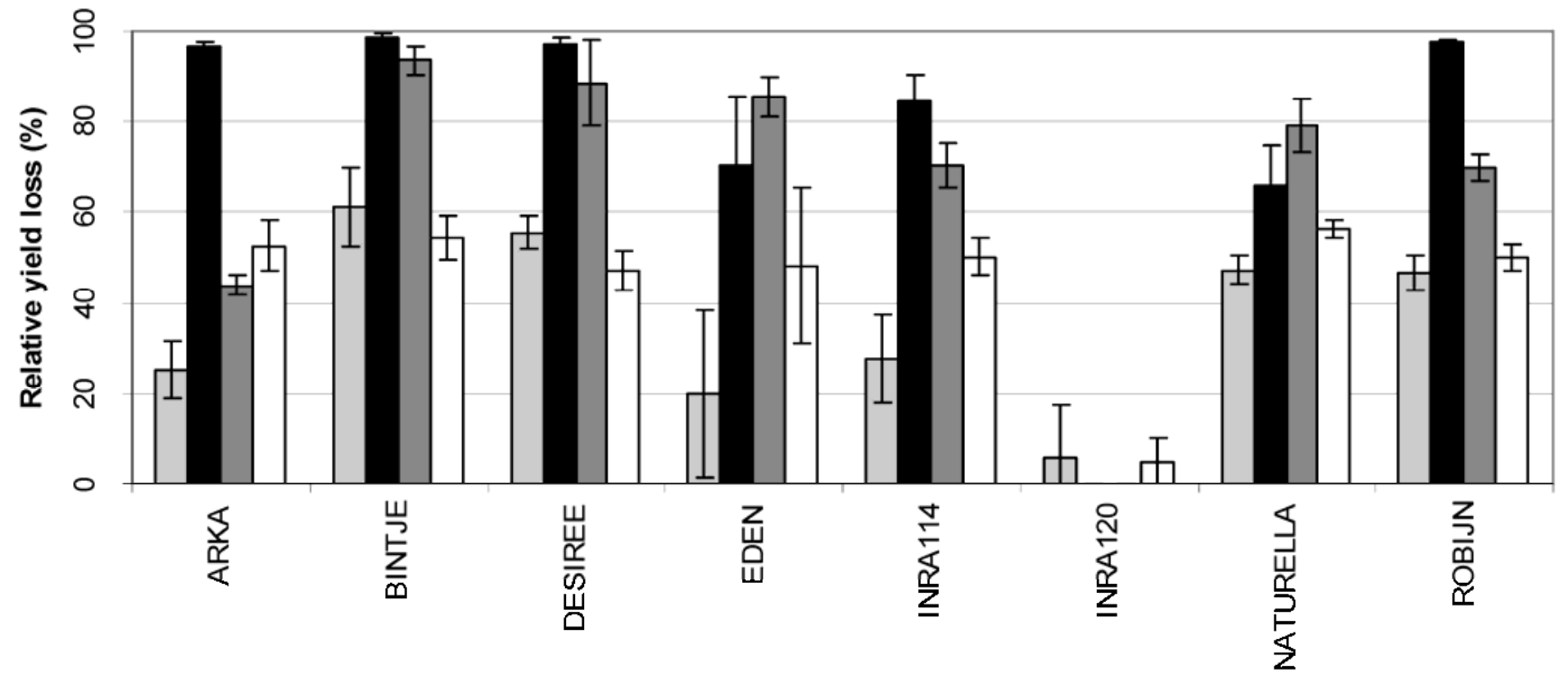

Fig. 3. Relative yield losses observed for eight cultivars in a 4-year experiment conducted at the INRA Ploudaniel station (Brittany, France). The bar color represents the year of observation: light gray (2006), black (2007), dark gray (2008), and white (2009). Error bars represent the $95 \%$ confidence intervals. 
tance factors they harbor. There were probably strains that have a different virulence and aggressiveness, due to constant shifts in the pathogen populations.

The significant differences in yield losses are fully explained by the types and levels of cultivar resistances (Fig. 3; Table 4). There was a large influence of the interaction of weather and cultivar resistance on the disease dynamics and yield loss. This is taken into account in the model by calculating the RAUDPC, showing that changes in the disease progression were used to predict yield losses due to late blight.

The model (35) successfully represented these interactions, indicating that its structure is suitable to take them into account. In addition to its good predictive quality (Fig. 4), this model is simple to use in terms of input variables, and has a relatively small number of 11 parameters (Table 3). It was not necessary to reestimate the parameters of the model. This is remarkable because these parameters were estimated more than 20 years ago on different cultivars, in another continent (North America), with different soil and weather conditions. This strongly suggests the robustness of the model. However, the Shtienberg model requires very detailed knowledge of varietal characteristics: the bulking rate for the disease-free cultivar, the physiological age at bulking initiation for a healthy crop (from emergence), and the physiological age at the end of bulking for a healthy crop (from emergence) This implies that it is usable only on well-characterized cultivars. Therefore, it appears useful to thoroughly characterize the maturity class of new cultivars as their market share increases in order to have robust damage functions for use with the Shtienberg model.

The calculation of physiological age using only the mean value of the effective vegetative development temperature of the crop between the minimum and maximum daily temperature proved to be a simple and efficient way to express daily changes of temperature. However, the calculation simplicity of this method does not compensate for the extra bias added. Therefore, it is recommended

Table 4. Relative yield losses associated on the eight cultivars types and levels of resistance over the four years of experiment

\begin{tabular}{|c|c|c|c|c|c|c|c|}
\hline \multirow[b]{2}{*}{ Cultivar } & \multirow[b]{2}{*}{ Type of resistance ${ }^{a}$} & \multirow[b]{2}{*}{ Resistance level } & \multicolumn{5}{|c|}{ Relative yield loss observed $(\%) \pm$ standard deviation $(n=3)$} \\
\hline & & & 2006 & 2007 & 2008 & 2009 & Mean $(n=4)$ \\
\hline Bintje & None & Very low & $61.1 \pm 7.8$ & $98.6 \pm 0.6$ & $93.5 \pm 2.8$ & $54.4 \pm 4.4$ & $76.9 \pm 22.4$ \\
\hline Désirée & Partial & Low & $55.5 \pm 3.3$ & $97.3 \pm 1.0$ & $88.4 \pm 8.4$ & $47.0 \pm 4.0$ & $72.1 \pm 24.6$ \\
\hline Arka & Specific (R1) and partial & Moderate to high & $25.4 \pm 5.6$ & $96.4 \pm 1.0$ & $43.9 \pm 1.9$ & $52.7 \pm 4.8$ & $54.6 \pm 30.1$ \\
\hline Eden & Specific and partial & Moderate & $19.8 \pm 16.3$ & $70.6 \pm 13.2$ & $85.4 \pm 3.8$ & $48.1 \pm 15.2$ & $56.0 \pm 28.6$ \\
\hline INRA 92T 11476 & Partial & Moderate & $27.7 \pm 8.8$ & $84.5 \pm 5.1$ & $70.4 \pm 4.2$ & $50.2 \pm 3.6$ & $58.2 \pm 24.8$ \\
\hline Naturella & Specific (overcome R2) & Low & $47.3 \pm 2.7$ & $66.0 \pm 7.8$ & $79.2 \pm 5.0$ & $56.2 \pm 1.7$ & $62.2 \pm 13.7$ \\
\hline Robijn & Partial & Moderate to high & $46.5 \pm 3.5$ & $97.5 \pm 0.7$ & $69.7 \pm 2.6$ & $50.0 \pm 2.5$ & $65.9 \pm 23.4$ \\
\hline INRA 92T 12016 & Specific and partial & Very high & $5.9 \pm 10.3$ & $0.0 \pm 0.0$ & $0.0 \pm 0.0$ & $5.1 \pm 4.5$ & $2.8 \pm 3.2$ \\
\hline
\end{tabular}

a Type of resistance according to genealogy and field observations.

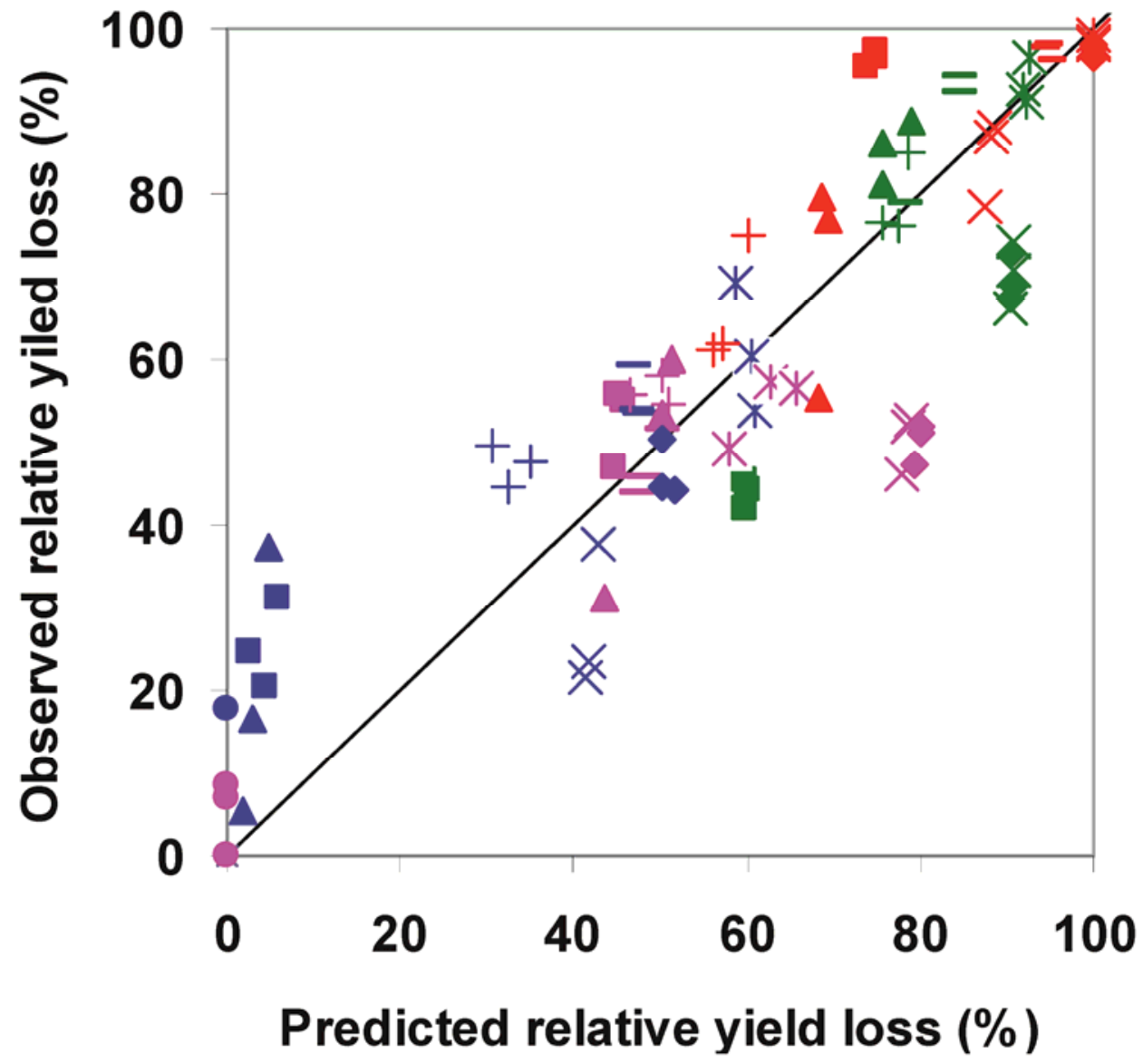

Fig. 4. Comparison of the relative yield losses predicted by the model of Shtienberg et al. (35) and the relative yield losses observed. The straight line is the 1:1 line. The blue, red, green, and yellow colors represent the years 2006, 2007, 2008, and 2009, respectively. Each symbol represents a cultivar: $\mathbf{~ I , ~ A r k a ; ~ * , ~ B i n t j e ; ~ - , ~ D e ́ s i r e ́ e ; ~} \mathbf{\Lambda}$, Eden; $\times$, INRA 92T 114 76; •, INRA 92T 120 16; +, Naturella; •, Robijn. 
to use the equation proposed by Sands et al. (31) to calculate physiological age.

The Shtienberg model proved to have a good quality of prediction for modern cultivars grown in French conditions. This will permit it to be used to improve potato late blight management not only at the tactical level (chemical control) but also at the strategic level (using IPM approaches that combine cultural, genetic, physical, and chemical control).

In Western Europe, and especially in France, the management of potato late blight mainly relies on the use of pesticides, which are used systematically over large areas on a long-term basis $(2,7)$. One way to improve this situation is to use decision support systems that attempt to target chemical applications at moments of $P$. infestans high risk (37). The Shtienberg model can improve operational disease warnings for potato late blight when conditions do not favor epidemics by basing warnings on potential damage. This model can be used in the same way as the damage functions embedded within the EPIPRE model (42) to help decide whether to spray, not to spray, or wait, based on expected economic benefits of the chemical treatment.
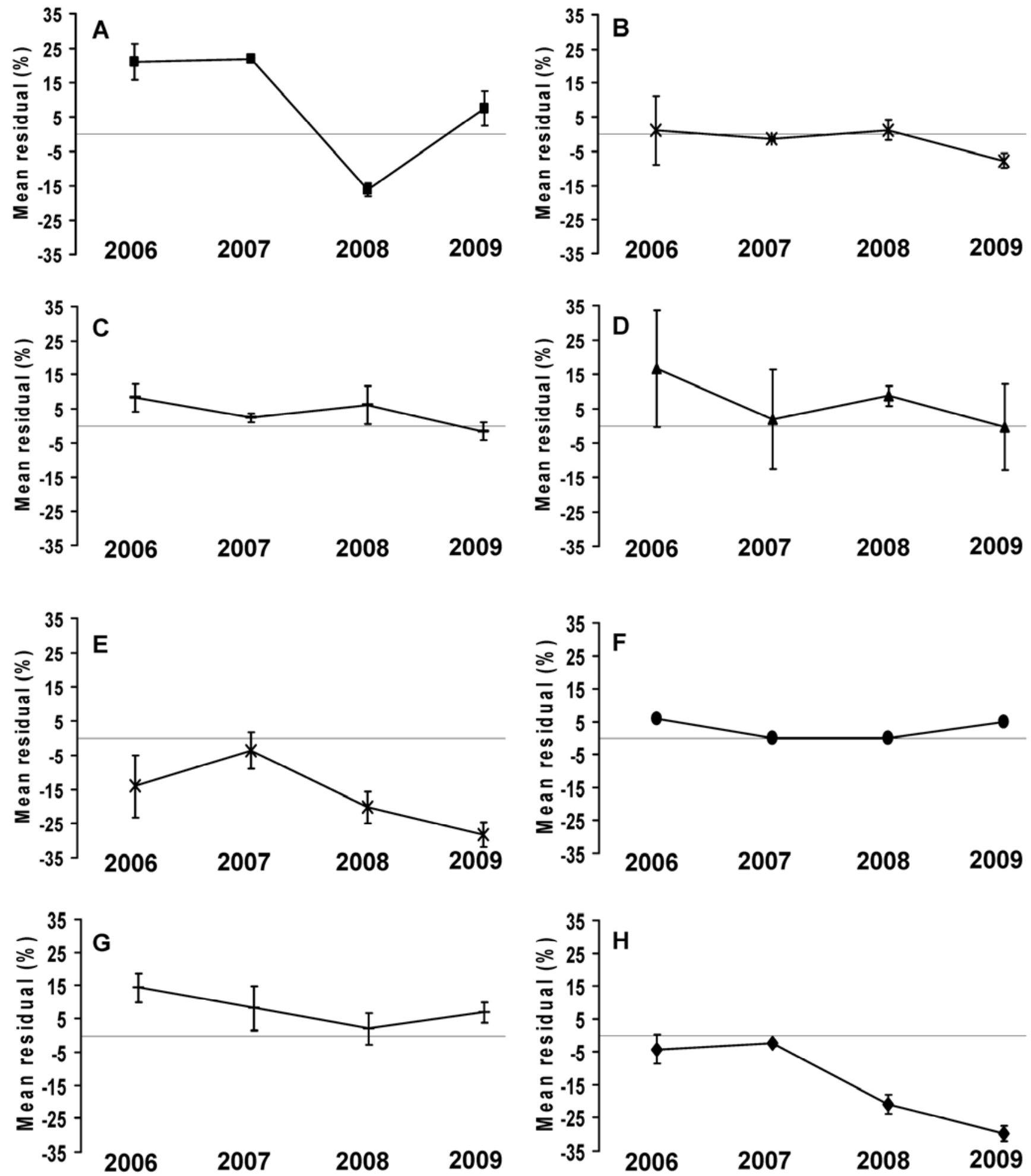

Fig. 5. Residuals analysis of relative yield loss of late blight in Ploudaniel in a 4-year experiment. Residuals were calculated as observed relative yield loss - predicted

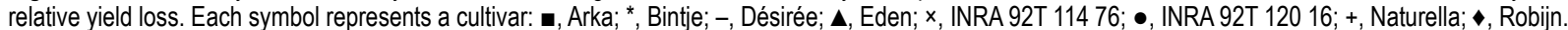


In addition to helping with tactical decision making, the evaluated model could contribute to the development of an integrated model to help design integrated management strategies of the disease, taking into account the agronomic, environmental, and socioeconomic performances of the studied cropping systems. This could be achieved by linking this model to an epidemiological model that predicts disease dynamics as a function of weather conditions, cultivar choice, and other cultural practices. Furthermore, approaches such as that followed by Lo-Pelzer et al. (22) could be developed to help design integrated strategies aimed at preserving the efficacy of quantitative or specific resistances.

\section{Acknowledgments}

This study was carried out within a Ph.D. project co-funded by INRA and the Association des Créateurs de Variétés Nouvelles de Pomme de Terre through a Conventions Industrielles de Formation par la Recherche grant and by the project MICMAC design (ANR-09-STRA-06) supported by the French National Agency for Research (ANR). Field experiments were partly supported by the ANR project ADD-CEDRE. We thank R. Corbière, L. Bousset, and D. Andrivon for their scientific support and essential inputs.

\section{Literature Cited}

1. Attoumani-Ronceux, A., Aubertot, J. N., Guichard, L., Jouy, L., Mischler, P., Omon, B., Petit, M. S., Pleyber, E., Reau, R., and Seiler, A. 2011. Guide pour la conception de systèmes de culture plus économes en produits phytosanitaires-application aux systèmes de polyculture, Ministère de l'agriculture, de l'alimentation, de la pêche, de la ruralité et de l'aménagement du territoire, Paris, France.

2. Aubertot, J. N., Barbier, J. M., Carpentier, A., Gril, J. J., Guichard, L., Lucas, P., Savary, S., Savini, I., and Voltz, M. 2007. Pesticides, agriculture and the environment: reducing the utilization of pesticides and limiting their environmental impacts. Expertise scientifique collective, INRA/CEMAGREF.

3. Aubertot, J. N., Schott, J. J., Penaud, A., Brun, H., and Doré, T., 2004. Methods for sampling and assessment in relation to the spatial pattern of Phoma stem canker (Leptosphaeria maculans) in oilseed rape. Eur. J. Plant Pathol. 110:183-192.

4. Aubertot, J. N., West, J. S., Bousset-Vaslin, L., Salam, M. U., Barbetti, M. J., and Diggle, A. J. 2006. Improved resistance management for durable disease control: a case study of Phoma stem canker of oilseed rape (Brassica napus). Eur. J. Plant Pathol. 114:91-106.

5. Bergamin Filho, A., Carneiro, S. M. T. P. G., Godoy, C. V., Amorim, L., Berger, R. D., and Hau, B. 1997. Angular leaf spot of Phaseolus beans: Relationships between disease, healthy leaf area, and yield. Phytopathology 87:506-515.

6. Bradeen, J. M., Lorizzo, M., Mollov, D. S., Raasch, J., Kramer, L. C., Millet, P. B., Austin-Phillips, S., Jiang, J., and Carputo, D. 2009. Higher copy numbers of the potato RB transgene correspond to enhanced transcript and late blight resistance levels. Mol. Plant-Microbe Interact. 22:437-446.

7. Champeaux, C. 2006. Recours à l'utilisation des pesticides en grandes cultures: évolution de l'indicateurs de fréquences de traitements au travers des enquêtes «pratiques culturales» du SCEE entre 1994 et 2001. Rapport INRA-Ministère de l'Agriculture et de la Pêche/INRA (Institut National de la Recherche Agronomique), UMR 211 Agronomie Grignon, ParisGrignon, France.

8. Danis, T. G., Karagiozoglou, D. T., Tsakiris, I. N., Alegakis, A. K., and Tsatsakis, A. M. 2011. Evaluation of pesticides residues in Greek peaches during 2002-2007 after the implementation of integrated crop management. Food Chem. 126:97-103.

9. Deguine, J. P., Ferron, P., and Russell, D. 2008. Sustainable pest management for cotton production. Annu. Rev. Agron. Sustain. Dev. 28:113-137.

10. Francl, L. J. 1989. Are physiological days of potato calculated accurately? Am. J. Potato Res. 66:391-395.

11. Fry, W. E., Apple, A. E., and Bruhn, J. A. 1983. Evaluation of potato late blight forecast modified to incorporate host resistance and fungicide weathering. Phytopathology 73:1054-1059

12. Gentleman, R., and Ihaka, R. 2000. Lexical scope in statistical computing. J. Comput. Graph. Stat. 9:491-508.

13. Haverkort, A. J., Struik, P. C., Visser, R. G. F., and Jacobsen, E. 2009. Applied biotechnology to combat late blight in potato caused by Phytophthora infestans Potato Res. 52:249-264.

14. James, W. C., Shih, C. S., Hodgson, W. A., and Callbeck, L. C. 1972. The quantitative relationship between late blight of potato and loss in tuber yield. Phytopathology 62:92-96.

15. Jeger, M. J., and Viljanen-Rollinson, S. L. H. 2001. The use of the area under the disease-progress curve (AUDPC) to assess quantitative disease resistance in crop cultivars Theor. Appl. Genet. 102:32-40.
16. Johnson, K. B., Johnson, S. B., and Teng, P. S. 1986. Development of a simple potato growth model for use in crop-pest management. Agric. Syst. 19:189-209.

17. Joosten, A. 1991. Geniteurslijst voor aardappelrassen. Commissie ter bevordering van het kweken en het onderzoek van neuwe aardappelrassen (C.O.A.), Wageningen, The Netherlands.

18. Kabat, P., Marshall, B., and van den Broek, B. J. 1995. Comparison of simulation results and evaluation of parameterization schemes. Pages 439501 in: Modelling and Parameterization of the Soil-Plant-Atmosphere System-A Comparison of Potato Growth Models. P. Kabat, B. Marshall, B. J. van den Broek, J. Vos, and H. van Keulen, eds. Wageningen Pers, Wageningen, The Netherlands.

19. Landeo, J. A., Gastelo, M., Forbes, G., Zapata, J. L., and Flores, F. J. 1996. Developing horizontal resistance to late blight in potato. Pages 122-126 in: Program Report 1995-96. International Potato Center, Lima, Peru.

20. Large, E. C. 1952. The interpretation of progress curves for potato late blight and other plant diseases. Plant Pathol. 1:109-117.

21. Latin, R. X, Mackenzie, D. R., and Cole, H., Jr. 1978. Crop loss prediction tables for potato late blight epidemics. Am. Potato J. 55:541-548.

22. Lô-Pelzer, E., Bousset, L., Jeuffroy, M. H., Salam, M.U., Pinochet, X., Boillot, M., and Aubertot, J. N. 2010. SIPPOM-WOSR: A simulator for integrated pathogen population management of Phoma stem canker on winter oilseed rape: I. Description of the model. Field Crops Res. 118:73-81.

23. Madden, L. V., Hughes, G., and van den Bosch, F. 2007. The Study of Plant Disease Epidemics. American Phytopathological Society, St. Paul, MN.

24. Miller, J. S., Cummings, T. F., Mikitzel, L. J., and Johnson, D. A. 2002 Influence of timing of harvest in relation to haulm killing and planting date on potato tuber rot caused by Phytophthora infestans. Plant Dis. 86:264 268.

25. Moriasi, D. N., Arnold, J. G., Van Liew, M. W., Bingner, R. L., Harmel, R. D., and Veith, T. L. 2007. Model evaluation guidelines for systematic quantification of accuracy in watershed simulations. Trans. ASABE 50:885-900.

26. Nash, J. E., and Sutcliffe, J. V. 1970. River flow forecasting through conceptual models: part 1. A discussion of principles. J. Hydrol. 10:282-290.

27. Nutter, F. W., Jr., Teng, P. S., and Royer, M. H. 1993. Terms and concepts for yield, crop loss, and disease thresholds. Plant Dis. 77:211-215.

28. Olofsson, B. 1968. Determination of the critical injury threshold for potato late blight (Phytophthora infestans). Waxtskyddsanst Stokholm 14:85-93.

29. Pfender, W. 2009. A damage function for stem rust of perennial ryegrass seed crops. Phytopathology 99:498-505.

30. Pilet F., Pellé R., Ellissèche D., and Andrivon D. 2005. Efficacy of the R2 resistance gene as a component for the durable management of potato late blight in France. Plant Pathol. 54:723-732.

31. Sands, P. J., Hackett, C., and Nix, H. A. 1979. A model of the development and bulking of potatoes (Solanum tuberosum L.). I. Derivation from well managed field crops. Field Crops Res. 2:309-331.

32. Savary, S., Teng, P. S., Willocquet, L., and Nutter, F. W., Jr. 2006. Quantification and modeling of crop losses: a review of purposes. Annu. Rev. Phytopathol. 44:89-112.

33. Savary, S., Willocquet, L., Elazegui, F. A., Castilla, N. P., and Teng, P. S. 2000. Rice pest constraints in tropical Asia: quantification of yield losses due to rice pests in a range of production situations. Plant Dis. 84:357-369.

34. Savary, S., and Zadoks, J. C. 1992. Analysis of crop loss in the multiple pathosystem groundnut-rust-late leaf spot. II. Study of the interactions between diseases and crop intensification in factorial experiments Crop Prot. 11:110-120.

35. Shtienberg, D., Bergeron, S. N. Nicholson, A. G., Fry, W. E., and Ewing, E. E. 1990. Development and evaluation of general model for yield loss assessment in potatoes. Phytopathology 80:466-472.

36. Singh, J. P., Govindakrishnan, P. M., Lal, S. S., and Aggarwal, P. K. 2005. Increasing the efficiency of agronomy experiments in potato using InfoCrop-POTATO model. Potato Res. 48:131-152.

37. Skelsey, P., Kessel, G. J. T., Rossing, W. A. H., and van der Werf, W. 2009 Parameterization and evaluation of a spatiotemporal model of the late blight pathosystem. Phytopathology 99:290-300.

38. Wallach, D., and Kletter, E. 1981. Prediction of boll opening in a cotton crop. Agron. J. 73:763-767.

39. Wallach, D., Makowski, D., and Jones, J. W. 2006. Evaluating crop models. Pages 11-53 in: Working with Dynamic Crop Models: Evaluation, Analysis Parameterization, and Applications. D. Wallach, D. Makowski, and J. W. Jones, eds. Elsevier, Amsterdam.

40. Yuan, F. M., and Bland, W. 2005. Comparison of light and temperaturebased index models for potato (Solanum tuberosum L.) growth and development. Am. J. Potato Res. 82:345-352.

41. Zadoks, J. C. 1985. On the conceptual basis of crop loss assessment: the threshold theory. Annu. Rev. Phytopathol. 23:455-73

42. Zadoks, J. C. 1989. EPIPRE, a computer-based decision support system for pest and disease control in wheat: its development and implementation in Europe. Plant Dis. Epidemiol. 2:3-29. 